Ana Delgado-Lima*, Maria C. Paiva and Ana Vera Machado

\title{
The influence of melt mixing on the stability of cellulose acetate and its carbon nanotube composites
}

DOI 10.1515/polyeng-2015-0388

Received September 7, 2015; accepted November 27, 2015

Abstract: Cellulose derivatives, such as cellulose acetate (CA), are commonly used due to their ease of processing. These polymers present interesting mechanical properties and biodegradability, but low thermal stability under melt processing conditions. Composites of carbon nanotubes (CNTs) and cellulose derivatives are expected to present enhanced properties, depending on the effect of nanotubes on polymer structure and thermal properties. This work aims to investigate the influence of melt mixing on the stability of CA and its CNT composites. Composites with $0 \mathrm{wt} \%, 0.1 \mathrm{wt} \%$ and $0.5 \mathrm{wt} \%$ CNTs, as received and functionalized with pyrrolidine groups, were prepared using a batch mixer and an extruder. Chain scission of CA occurred during processing, but the effect was considerably reduced in the presence of CNTs. The incorporation of small amounts of CNTs (with or without functionalization) decreased polymer degradation by thermomechanical effects induced during polymer processing.

Keywords: carbon nanotubes; degradation; functionalization; thermal properties.

\section{Introduction}

Carbon nanotubes (CNTs) have been extensively used as a reinforcement in recent years, mainly due to their high performance and excellent electrical properties [1, 2]. The integration of these nanometric particles with high area to volume ratio, in polymer matrix, has the potential to enhance the composite properties at small CNT loads [3].

\footnotetext{
*Corresponding author: Ana Delgado-Lima, Institute for Polymers and Composites/I3N, University of Minho, Azurém, 4800-0581 Guimarães, Portugal, e-mail: ana.lima@dep.uminho.pt. http://orcid.org/0000-0002-6712-4812

Maria C. Paiva and Ana Vera Machado: Institute for Polymers and Composites/I3N, University of Minho, Azurém, 4800-0581 Guimarães, Portugal
}

Several polymers have been investigated as matrix for CNT composites [4]. Natural polymers are particularly interesting, as they do not pose environmental problems at the end of their lifetime [4]. Amongst all biopolymers, cellulose is the most abundant natural polymer on earth, presenting excellent mechanical properties due to its highly crystalline structure. This characteristic turns out to be a major drawback for polymer processing, as it renders the polymer infusible and insoluble in common solvents and thus difficult to shape [5-7]. To overcome this problem, cellulose acetate (CA) is a commonly used derivative that is processable, biodegradable and a non-toxic polymer $[5,6,8]$. It can be employed as a matrix to develop materials with tailored properties by adding CNTs or others compounds. Due to industry demand for cost effective production, the bio-nanocomposites should be produced by industry-ready technologies such as those based on melt mixing [9]. Nowadays, most CA or cellulose/CNT novel composites are produced using solution-based techniques [10-17]. Switching to melt mixing processing would bring the advantage of a low environmental impact due to the solvent-free nanocomposite preparation $[9,18]$. Since cellulose-based polymers are prone to thermal degradation, it is important to investigate the effect of CNT addition on polymer structure and molecular weight during processing using conventional melt mixing techniques [19, 20]. Also, CNTs are frequently covalently functionalized to improve the polymer/CNT interface in the composite. The functional groups bonded to the CNT may react with the polymer, inducing reactions that would not take place otherwise. In this work, the CNT surface was functionalized by the 1,3-dipolar cycloaddition of azomethine ylides using a one-pot solvent-free experimental procedure reported elsewhere [21]. The functionalized nanotubes, CNTNH, were characterized by thermogravimetric analysis (TGA) showing a weight loss of approximately $15 \%$ at $800^{\circ} \mathrm{C}$, similar to the results obtained in previous studies [21]. According to those studies, the functional groups bonded to the CNTs under these conditions are mainly pyrrolidine (Figure 1). Also, and in comparison with the work of other authors such as Li et al. [22], who bonded carboxylic acid groups, this kind of functionalization is 

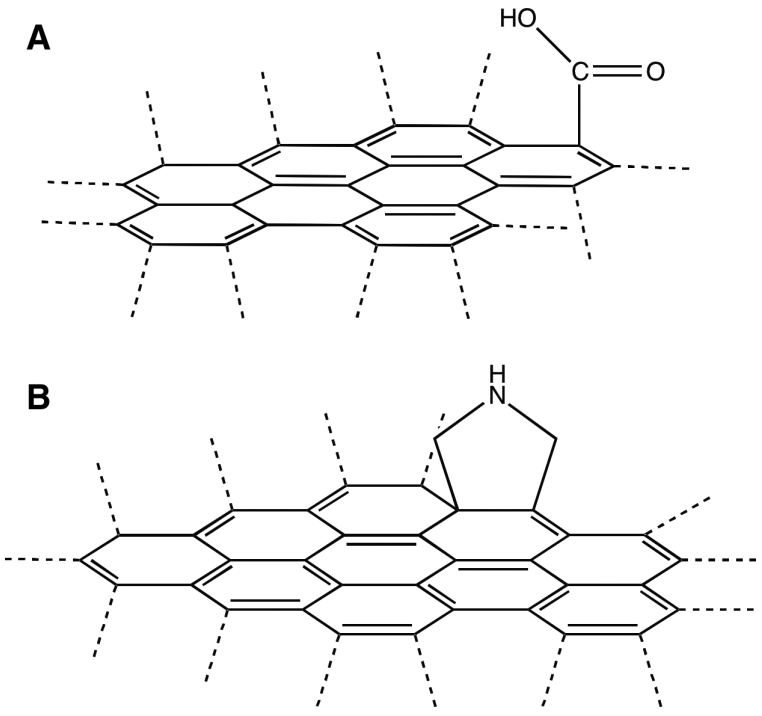

Figure 1: (A) Carbon nanotube functionalization with acidic groups; (B) less aggressive functionalization with pyrrolidine groups.

both less aggressive for the CNTs and for the environment, since it does not use combinations of strong oxidizing acids (Figure 1). Thus, nanocomposites of CA/CNT were prepared by melt mixing using $0.1 \mathrm{wt} \%$ and $0.5 \mathrm{wt} \% \mathrm{CNTs}$, both in a batch mixer and a mini twin-screw extruder. The produced materials were characterized in terms of the CA molecular weight distribution and thermal properties.

\section{Materials and methods}

\subsection{Materials}

The CNTs were multiwall from Nanocyl (Nanocyl SA, Belgium), NC 7000, produced via a catalytic carbon vapor deposition process with an average diameter and length of $9.5 \mathrm{~nm}$ and $1.5 \mu \mathrm{m}$, respectively. All of the chemicals were purchased from Sigma-Aldrich (Sigma-Aldrich Quimica, S.L., Sintra, Portugal), including benzyloxycarbonylglycine (Z-Gly-OH 99\%), paraformaldehyde (reagent grade), diethyl ether, ethanol and $\mathrm{n}$-hexane, and were used without further purification. The CA with an acetylation degree of $39.8 \mathrm{wt} \%$ was also acquired from Sigma-Aldrich.

\subsection{Preparation of the nanocomposites}

The functionalization of the CNT surface was accomplished via 1,3-dipolar cycloaddition reaction of the azomethine ylide formed by the reaction of Z-Gly-OH with paraformaldehyde, according to a procedure reported elsewhere [21]. Cellulose-based nanocomposites were prepared by melt compounding using two pieces of equipment: an intensive batch mixer (Haake Rheomix $600 \mathrm{OS}, \mathrm{v}=60 \mathrm{~cm}^{3}$ ) and a MicroLab co-rotating twin-screw extruder Rondol $(\mathrm{L} / \mathrm{D}=20 / 1$, nominal screw diameter $=10 \mathrm{~mm}$, die $=2 \mathrm{~mm}$ ). Nanocomposites with $0.1 \mathrm{wt} \%$ and $0.5 \mathrm{wt} \%$ of functionalized and non-functionalized CNTs were prepared in the batch mixer at $230^{\circ} \mathrm{C}$ with a rotor speed of $100 \mathrm{rpm}$ during $8 \mathrm{~min}$. In the extruder, the samples were produced under constant processing conditions, at a screw speed of $100 \mathrm{rpm}$ and a temperature profile along the extruder barrel between $130^{\circ} \mathrm{C}$ and $250^{\circ} \mathrm{C}$ using a throughput of $1.4 \mathrm{~g} / \mathrm{min}$. In both cases, CA and CNTs were previously dried in an oven at $80^{\circ} \mathrm{C}$ overnight and pre-mixed before processing.

\subsection{Characterization}

The molecular weight of $\mathrm{CA}$ and respective nanocomposites was determined by gel permeation chromatography using a GPC Waters Alliance 2695. The samples were dissolved in tetrahydrofuran $(1.5 \mathrm{mg} / \mathrm{ml})$, and the homogeneous solution was filtered through a syringe filter (hydrophobic polytetrafluoroethylene) with a pore size of $0.45 \mu \mathrm{m}$ before injection. The measurements were performed at a flow rate of $1 \mathrm{ml} / \mathrm{min}$ and $80 \mu \mathrm{l}$ of each solution were injected in a system containing three PLgel MIXED-B columns $(7.5 \mathrm{~mm} \times 300 \mathrm{~mm}$, particle size $10 \mu \mathrm{m})$ at $25^{\circ} \mathrm{C}$ and a refractive index-detector at $35^{\circ} \mathrm{C}$.

Differential scanning calorimetry measurements (Table 1) were performed on Perkin Elmer Diamond equipment under flowing argon atmosphere between

Table 1: Thermal properties of the cellulose acetate and nanocomposites.

\begin{tabular}{llrrrr}
\hline Samples & & $\operatorname{Tg}\left( \pm 1^{\circ} \mathrm{C}\right)$ & $\operatorname{Tm}\left( \pm 1^{\circ} \mathrm{C}\right)$ & $\boldsymbol{\chi \chi \chi}_{\mathrm{c}}(\%)$ \\
\hline CA & & & 208.0 & - & - \\
CA(HK) & & & 190.6 & 206.2 & 3.9 \\
CA(ME) & & & 188.7 & 215.3 & 2.9 \\
CA+0.1\% & CNT & HK & 187.2 & 208.0 & 3.8 \\
& & ME & 190.9 & 216.6 & 3.6 \\
& \multirow{2}{*}{ CNTNH } & HK & 190.8 & 209.4 & 4.3 \\
& & ME & 189.5 & 216.0 & 4.3 \\
CA+0.5\% & CNT & HK & 190.7 & 209.2 & 6.3 \\
& & ME & 189.1 & 217.0 & 5.6 \\
& \multirow{2}{*}{ CNTNH } & HK & 190.7 & 213.1 & 6.3 \\
& & ME & 193.1 & 217.7 & 5.5 \\
\hline
\end{tabular}

CA, Cellulose acetate; CNT, carbon nanotube; CNTNH, functionalized nanotubes; HK, batch mixer; ME, mini-extruder; Tg, glass transition temperature; $\mathrm{Tm}$, melting temperature; $\chi_{c}$, crystallization degree. 
$30^{\circ} \mathrm{C}$ and $270^{\circ} \mathrm{C}$ at a heating rate of $10^{\circ} \mathrm{C} / \mathrm{min}$. The melting temperature ( $\mathrm{Tm})$ was determined as the peak onset temperature and the crystallinity degree was calculated using Eq. (1), where $\Delta H$ was determined for each sample, $\Phi$ corresponds to the mass fraction of the CNTs for the nanocomposites, and the value of $\Delta H_{f}^{0}$ of CA was $58.8 \mathrm{~J} / \mathrm{mol}[23]$ :

$$
\chi_{c}(\%)=\frac{\Delta H_{f}(\text { Sample })}{(1-\Phi) \Delta H_{f}^{0}(\mathrm{CA})} \times 100
$$

TGA measurements were performed on a TGA Q500 from TA Instruments under a nitrogen constant flow. CNT functionalization was confirmed by a temperature sweep between $100^{\circ} \mathrm{C}$ and $800^{\circ} \mathrm{C}$ at $10^{\circ} \mathrm{C} / \mathrm{min}$, starting with an isothermal plateau at $100^{\circ} \mathrm{C}$ during $2 \mathrm{~min}$. The analysis of the nanocomposites was performed by a temperature sweep between $30^{\circ} \mathrm{C}$ and $600^{\circ} \mathrm{C}$ at a heating rate of $10^{\circ} \mathrm{C} / \mathrm{min}$ to evaluate the thermal stability of the material.

\section{Results and discussion}

\subsection{Gel permeation chromatography analysis}

Gel permeation chromatography chromatograms of the polymer matrix before and after processing are presented in Figure 2. Before processing, CA presents a lower retention time, which is associated with higher molecular weight. After processing in a batch mixer, HK, and twinscrew extruder, ME, the chromatogram curves shifted to higher retention times, indicating a molecular weight decrease. This may be enhanced by hydrolysis of the
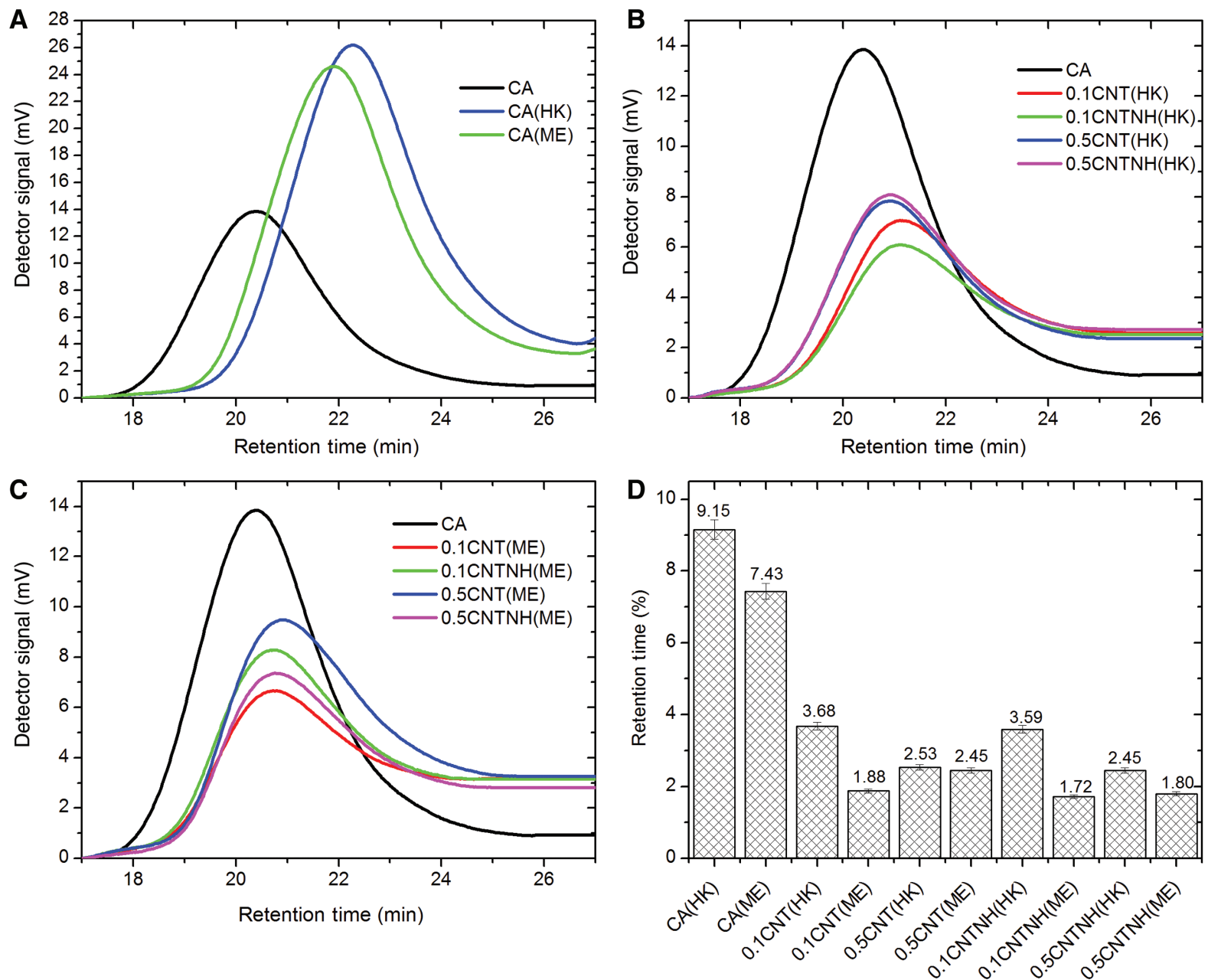

Figure 2: (A) Gel permeation chromatography (GPC) chromatograms of cellulose acetate before and after processing; (B) and (C) GPC chromatograms of cellulose acetate (CA) from the composites prepared in the batch mixer, HK and mini-extruder, ME, respectively, compared with pure CA processed by the same process; (D) \% variation of retention time of CA and nanocomposites. 
glycosidic bonds, due to residual moisture, accelerated by temperature and catalyzed by the acetic acid product of deacetylation [24-26]. Also, the CA processed in the ME systematically showed higher molecular weight compared to the CA processed in the HK. In spite of the higher shear forces developed in the ME, the longer residence time in the HK ( 8 min in HK vs. 4 min in ME) seems to have a strong effect on polymer chain scission. These samples also show broader peaks when compared to CA before processing, which can be associated to a higher polydispersity. In order to understand the effect of the processing method on CA molecular weight, the percent variation of the retention time $[\mathrm{RT}(\%)]$ at the curve maximum, $\left(R T_{\chi}\right)$, was measured for each material, relative to as received CA $\left(R T_{C A}\right)$ using:

$$
\mathrm{RT}(\%)=\frac{R T_{x}-R T_{C A}}{R T_{C A}} \times 100
$$

$\mathrm{RT}(\%)$ is proportional to the polymer average molecular weight, the greater RT corresponding to the lower polymer average molecular weight (Figure 2). Therefore, it is evident that the presence of CNTs, either pristine or functionalized, decreased the polymer degradation, and this effect is independent of their concentration, at least from $0.1 \mathrm{wt} \%$ to $0.5 \mathrm{wt} \%$ of CNTs. The presence of the CNTs in this case could act as a physical barrier for the acetic acid produced during the deacetylation of CA, delaying the chain-scission of the nanocomposite, since the produced acetic acid promotes the rupture of the glycosidic bonds. All of the nanocomposites processed in the HK showed greater CA degradation compared to the extruded ones.

\subsection{Thermal stability of the nanocomposites}

The thermograms of CA before processing (CA), after processing in a batch mixer (CA[HK]) and in the mini-extruder, (CA[ME]) (Figure 3) present an onset of thermal degradation, under nitrogen at $323^{\circ} \mathrm{C}, 342^{\circ} \mathrm{C}$ and $349^{\circ} \mathrm{C}$, respectively. Moreover, the polymer is completely degraded at approximately $360^{\circ} \mathrm{C}, 385^{\circ} \mathrm{C}$ and $392^{\circ} \mathrm{C}$, respectively. According to Zavastin et al. [27] the weight loss of CA corresponds to the pyrolysis of the polymer backbone followed by deacetylation. Pure CA exhibits lower thermal stability
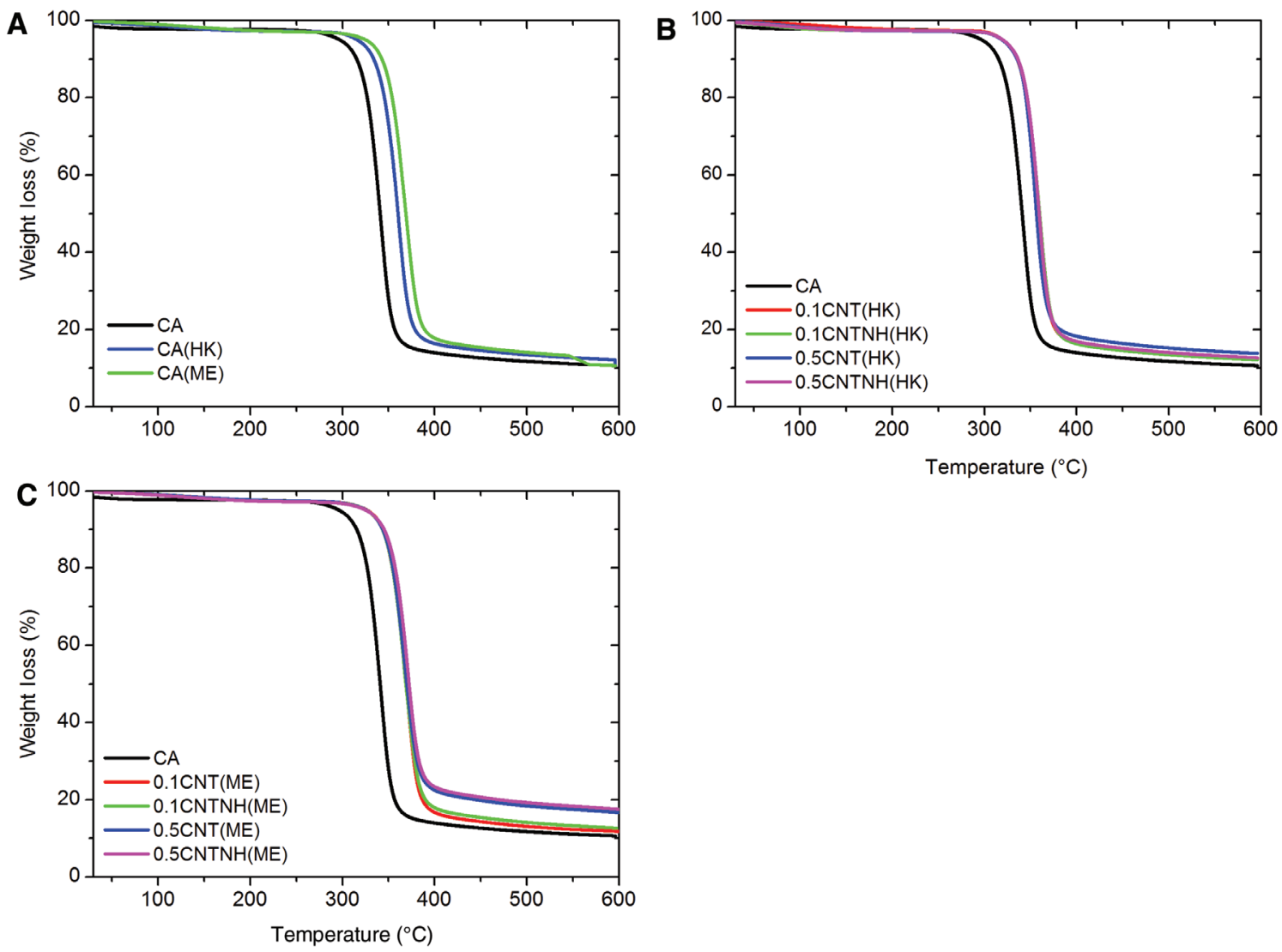

Figure 3: Thermal stability of (A) pure cellulose acetate (CA) and processed CA; (B) pure CA with carbon nanotube (CNT) and functionalized nanotubes CNTNH processed in the Haake mixer; and $(C)$ in the mini-extruder. 
before processing compared to CA after processing, in spite of its higher molecular weight. Li et al. [22] observed that the incorporation of CNTs functionalized with carboxylic groups on the CA polymer improved the thermal stability of the nanocomposite. In the present study, a similar trend is noticed for nanocomposites prepared using CNTs or functionalized CNTNH (Figure 3). Although, CA/CNT nanocomposites showed a lower molecular weight comparing to the as-received CA polymer, this result indicates that the incorporation of CNTs could lead to the stabilization of the CA polymer matrix, resulting in the improvement of the thermal stability of CA/CNTs nanocomposites. In this case, the CNTs may be increasing the thermal conductivity, homogenizing the composite temperature and reducing thermal gradients generated across the insulating material, thus reducing thermal degradation, and enhancing its thermal stability. The CNT may also provide a physical barrier against the diffusion of the volatile products generated during thermal decomposition, such as, acetic acid for the CA polymer matrix, which may catalyze polymer degradation. This physical barrier effect was already observed on poly(terephthalate of ethylene)/CNT and on poly(ethylene 2,6-naphthalate)/CNT nanocomposites $[28,29]$. The samples prepared in the ME show higher thermal stability, probably due to the higher molecular weight of these materials compared to those prepared in the HK (Figure 3). Table 1 presents the differential scanning calorimetry results obtained for the glass transition, onset $\mathrm{Tm}$ and the crystallinity degree of pure CA and nanocomposites. The onset $\mathrm{Tm}$ and the degree of crystallinity of CA show a similar trend, as the results obtained by TGA (Figure 3). CA nanocomposites prepared in the ME exhibit higher Tm than the materials prepared in the $\mathrm{HK}$, which can be associated with the larger degradation during sample preparation in the latter. The crystallization degree calculated is also in agreement with the previous analyses showing a measurable crystallinity, although incipient, for the samples processed in the HK and the ME. The crystalline domains could originate on the organization of the shorter macromolecular chains formed due to chain-scission during processing. Furthermore, the presence of the functionalization in the CNTs did not significantly affect the glass transition and Tm, as well as the crystallinity degree.

\section{Conclusion}

The effect of CNTs and functionalized CNTs with pyrrolidine groups on the polymer structure and thermal properties of cellulose nanocomposites during preparation by melt mixing was successfully investigated. The incorporation of small amounts of CNT (with or without functionalization) enhanced the composite stability by delaying the polymer degradation by thermomechanical effects induced during polymer processing. Despite polymer degradation, the processed $\mathrm{CA}$ and respective nanocomposites presented higher thermal stability compared to the as-received CA. The functionalized CNTs could withstand the processing conditions, since the composites thermal properties were similar to those of the composites with non-functionalized CNT. The samples prepared in the mini-extruder experienced less degradation during processing, emphasizing the relevance of the processing conditions on the final composite properties.

Acknowledgments: The authors acknowledge the Portuguese Foundation for Science and Technology (SFRH/ BD/81711/2011) and n-STeP - Nanostructured systems for Tailored Properties, with reference NORTE-07-0124FEDER-000039, supported by the Programa Operacional Regional do Norte (ON.2).

\section{References}

[1] Reddy MM, Vivekanandhan S, Misra M, Bhatia SK, Mohanty AK. Prog. Polym. Sci. 2013, 38, 1653-1689.

[2] Aryasomayajula, Wolter K-J. J. Nanotechnol. 2013, 2013.

[3] Ma P-C, Siddiqui NA, Marom G, Kim J-K. Composites, Part A 2010, 41, 1345-1367.

[4] Miller R-J. Biodegradability of Polymer: Regulations and Methods for Testing, John Wiley and Sons, Inc.: Published Online, 2005.

[5] Li Y, Wu M, Liu R, Huang YM. Sol. Energy Mater. Sol. Cells 2009, 93, 1321-1328.

[6] Schiffman JD, Schauer CL. Polym. Rev. 2008, 48, 317-352.

[7] Jeon GW, An J-E, Jeong YG. Composites, Part B 2012, 43, 3412-3418.

[8] Gutiérrez MC, De Paoli M-A, Felisberti MI. Ind. Crops Prod. 2014, 52, 363-372.

[9] Barmpalexis P, Koutsidis I, Karavas E, Louka D, Papadimitriou SA, Bikiaris DN. Eur. J. Pharm. Biopharm. 2013, 85, 1219-1231.

[10] El Badawi N, Ramadan AR, Esawi AMK, El-Morsi M. Desalination 2014, 344, 79-85.

[11] Liu B-T, Hsu C-H, Wang W-H. J. Taiwan Inst. Chem. Eng. 2012, 43, 147-152.

[12] Luo Y, Wang S, Shen M, Qi R, Fang Y, Guo R, Cai H, Cao X, Tomas H, Zhu M, Shi X. Carbohydr. Polym. 2013, 91, 419-427.

[13] Madaeni SS, Derakhshandeh K, Ahmadi S, Vatanpour V, Zinadini S. J. Membr. Sci. 2012, 389, 110-116.

[14] Qi H, Mäder E, Liu J. Sens. Actuators, B 2013, 185, 225-230.

[15] Rahatekar SS, Rasheed A, Jain R, Zammarano M, Koziol KK, Windle AH, Gilman JW, Kumar S. Polymer 2009, 50, 4577-4583. 
[16] Wan J, Yan X, Ding J, Ren R. Sens. Actuators, B 2010, 146, 221-225.

[17] Wu X, Zhao F, Varcoe JR, Thumser AE, Avignone-Rossa C, Slade RC. Bioelectrochemistry 2009, 77, 64-68.

[18] Zepon KM, Vieira LF, Soldi V, Salmoria GV, Kanis LA. Polym. Test. 2013, 32, 1123-1127.

[19] Spitalsky Z, Tasis D, Papagelis K, Galiotis C. Prog. Polym. Sci. 2010, 35, 357-401.

[20] Liu P. Eur. Polym. J. 2005, 41, 2693-2703.

[21] Paiva MC, Simon F, Novais R, Ferreira T, Proença M, Xu W, Besenbacher F. ACSNano 2010, 4, 7379-7386.

[22] Li M, Kim I-H, Jeong YG. J. Appl. Polym. Sci. 2010, 118, 2475-2481.

[23] Barud HS, Araújo Júnior AM, Santos DB, Assunção RMN, Meireles CS, Cerqueira DA, Rodrigues Filho G, Ribeiro CA,
Messaddeq Y, Ribeiro SJL. Thermochim. Acta 2008, 471, 61-69.

[24] Littlejohn D, Pethrick RA, Quye A, Ballany JM. Polym. Degrad. Stab. 2013, 98, 416-424.

[25] Rambaldi DC, Suryawanshi C, Eng C, Preusser FD. Polym. Degrad. Stab. 2013, 107, 237-245.

[26] Knight B. Polym. Degrad. Stab. 2014, 107, 219-222.

[27] Zavastin D, Cretescu I, Bezdadea M, Bourceanu M, Drăgan M, Lisa G, Mangalagiu I, Vasić V, Savić J. Colloids Surf. A 2010, 370, 120-128.

[28] Young J, Hun S. In High Performance PET/Carbon Nanotube Nanocomposites: Preparation, Characterization, Properties and Applications, Ebrahimi F, Ed., InTech: 2012, p 97-121.

[29] Kim JY, Han SI, Hong S. Polymer 2008, 49, 3335-3345. 